framum

Sociológico

\section{Forum Sociológico}

Série II

33 | 2018

Número 33

\title{
Urbanismo de marca e lugares de adoração. Reflexões a partir de uma viagem a Lisboa
}

Urbanismo de marca y lugares de culto. Reflexiones a partir de un viaje a Lisboa ${ }^{i}$ Place branding and places of worship. Reflections from a trip to Lisbon

\section{Samuel Fernández Ignacio}

\section{(2) OpenEdition}

\section{Journals}

\section{Edición electrónica}

URL: https://journals.openedition.org/sociologico/2376

DOI: 10.4000/sociologico.2376

ISSN: 2182-7427

Editor

CICS.NOVA - Centro Interdisciplinar de Ciências Sociais da Universidade Nova de Lisboa

Edición impresa

Paginación: 19-28

ISSN: 0872-8380

\section{Referencia electrónica}

Samuel Fernández Ignacio, «Urbanismo de marca e lugares de adoração. Reflexões a partir de uma viagem a Lisboa», Forum Sociológico [En línea], 33 | 2018, Puesto en línea el 30 diciembre 2018, consultado el 30 marzo 2022. URL: http://journals.openedition.org/sociologico/2376 ; DOI: https:// doi.org/10.4000/sociologico. 2376 


\title{
URBANISMO DE MARCA Y LUGARES DE CULTO. REFLEXIONES A PARTIR DE UN VIAJE A LISBOA ${ }^{1}$
}

URBANISMO DE MARCA E LUGARES DE ADORAÇÃO. REFLEXÕES A PARTIR DE UMA VIAGEM A LISBOA

\section{PLACE BRANDING AND PLACES OF WORSHIP. REFLECTIONS FROM A TRIP TO LISBON}

Samuel Fernández Ignacio

Escuela de Arte y Superior de Diseño Pablo Picasso, España

\begin{abstract}
Resumen
El marketing ha reducido a mercancía el mundo religioso. Por otro lado, los discursos publicitarios han difundido una ideología que sacraliza el rol que juegan los productos dentro de las prácticas rituales de la vida cotidiana. Las mercancías culturales permiten a los individuos distinguirse en sus elecciones de consumo, confeccionando un corpus de creencias y valores que configuran formas alternativas de experimentar lo religioso al margen de las iglesias. El presente artículo explora las posibles semejanzas que se pueden dar entre: 1) las lógicas que guían la producción simbólica de los escenarios urbanos del capitalismo avanzado y 2) las que habitualmente se relacionan con la experiencia de lo sagrado.
\end{abstract}

Palabras clave: marketing urbano, disneyficación, religión

\section{Resumo}

O marketing reduziu o mundo religioso a mercadoria. Por outro lado, os discursos publicitários propagaram uma ideologia que santifica o papel que os produtos desempenham dentro das práticas rituais da vida diária. Os bens culturais permitem aos indivíduos distinguirem-se nas suas escolhas enquanto consumidores, constituindo um corpus de crenças e valores que moldam formas alternativas de experimentar o religioso fora das igrejas. O presente artigo explora as possíveis semelhanças entre: 1) as lógicas que orientam a produção simbólica dos cenários urbanos do capitalismo avançado e 2) aquelas que geralmente estão relacionadas com a experiência do sagrado.

Palavras-chave: marketing urbano, disneyfication, religião

\begin{abstract}
The religious world has been reduced by marketing to a mere commodity. Yet, at the same time, advertising has disseminated an ideology which sacralizes the role that products play in ritual practices of daily life. Cultural goods allow individuals to distinguish themselves and be recognized through their consumption choices creating a corpus of beliefs and values that shape alternative ways of experiencing religion outside the churches. This article explores the possible similarities between: 1 ) the logics underlying the symbolic production of the urban settings of advanced capitalism, and 2) those that usually relate to the experiences of the sacred.
\end{abstract}

Keywords: urban marketing, disneyfication, religion 


\section{Introducción}

El texto que se presenta a continuación se enmarca teóricamente en el campo de una sociología urbana que indaga en los principales cambios que la adopción del enfoque económico neoliberal ha producido en las ciudades de finales siglo XX. A partir de la década de 1980, nuevas dinámicas espaciales del mercado de bienes y servicios en una economía globalizada, imprimieron un nuevo rol a la gestión de los territorios. El empresarialismo urbano (Harvey, 2007) surge en esa década conceptualizando el territorio como mercancía producida gracias a la intervención de las industrias culturales y creativas. Los discursos empleados para la venta de esta mercancía adoptarán desde principios de la década de 1990, los postulados del branding, rama del marketing centrada en el proceso de construcción de marcas. La evolución de los mercados internacionales, la deslocalización de gran parte de la industria y la lógica cultural inserta en la producción de mercancías en las sociedades del capitalismo avanzado han impulsado la aparición de un marketing territorial que rediseña identidades recurriendo al fetiche de la marca.

Es objetivo de este artículo exponer cómo en las actuales economías urbanas los aspectos simbólicos lejos de poder aislarse de la realidad material, se encuentran plenamente incorporados en la estructura económica que es motor de una continua reconversión identitaria. Las ideas de autores como Zygmunt Bauman, Saskia Sassen o Richard Florida, se combinan con enfoques etnográficos próximos a Edmund Leach y Clifford Geertz. La metodología que se ha empleado para el análisis de la realidad urbana, en vez de recurrir a parámetros cuantitativos, resultados de encuestas o grupos de discusión, se fundamenta en una estrategia investigadora que ha sido definida como observación flotante (Delgado, 2003). Nuestro breve trabajo de campo en la ciudad de Lisboa y en la localidad de Fátima, se ha guiado por la práctica de una mirada etnográfica que encuadrada en la antropología simbólica, encuentra afinidades con los análisis iconográficos continuadores de la tradición iniciada por Erwin Panofsky.

Emulando a Umberto Eco, (Eco, 2012, pp. 15-82) a mediados de julio de 2017 realizo un viaje en coche desde A Coruña hasta Lisboa para comparar diferentes realidades urbanas. Al poco de llegar a la capital portuguesa cae en mis manos un mapa en el que se encuentran señalados los principales museos y monumentos de interés. Al dorso de este mapa figuraban una serie de lugares relativamente cercanos a la capital que se recomendaban como excursiones para realizar en un día. Llama mi atención el hecho de que junto al Santuario de Fátima apareciese Freeport, un centro de shopping (Imagen 1).
Imagen $1 \triangleright$ Fotografía de folleto turístico

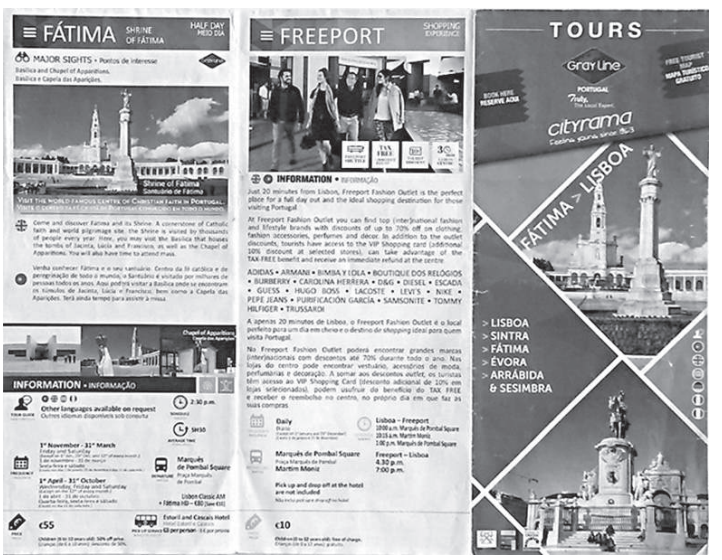

Fuente: Elaboración propia.

En cierto modo no había nada extraño en esa guía puesto que los grandes centros comerciales han sido calificados muchas veces como "catedrales del siglo XXI". A partir de esta coincidencia, mi deriva por la capital portuguesa estuvo acompañada por la reflexión en torno a la confluencia que existe entre urbanismo, religión y consumo turístico.

Para contextualizar mi análisis en una escala geográfica más amplia, conviene recordar que en los extremos del denominado Eje Atlántico, eurorregión que se extiende desde el norte de Galicia hasta Lisboa (Mapa 1), se encuentran dos de los principales centros de peregrinación de la Cristiandad: 1) el Sepulcro del Apóstol Santiago y 2) el Santuario de Fátima. No es mi intención narrar la historia de estos lugares, consagrados a la misma religión (catolicismo). Simplemente me interesa destacar ahora que estos dos centros religiosos surgieron ligados a una idea de misión divina que debía completarse. El Sepulcro del Apóstol Santiago, localizado en la ciudad de Santiago de Compostela, se remonta al supuesto descubrimiento de sus restos mortales en el siglo IX, en un espacio recientemente conquistado a los musulmanes por el cristiano Reino de Asturias. La iconografía de Santiago Matamoros (Imagen 2) representa al Apóstol interviniendo milagrosamente en favor de los cristianos cuando casi la totalidad de la península Ibérica era Al-Ándalus, territorio dominado por los musulmanes. La historia del Santuario de Fátima comienza a principios del siglo XX a partir de una milagrosa aparición de la Virgen María. Este fenómeno sobrenatural se produjo de forma repetida durante el año de 1917 , en un pequeño núcleo rural del interior de Portugal a poco más de 100 kilómetros de la capital del país. Según relatan las crónicas del suceso, durante sus apariciones la Virgen María revela una serie de secretos a tres niños pastores (Tetlow, Okland \& Myers, 2011). Entre las advertencias transmitidas, figuraba el anuncio 
de que la revolución bolchevique que triunfaría en Rusia ese mismo año, no representaba un camino hacia la liberación de los males que atañen a la sociedad. Tanto en el caso de Santiago como en el de Fátima, la religión fue instrumento político. Las peregrinaciones aglutinaron al cuerpo social alrededor de programas iconográficos que funcionaron como banderas nacionales.

Mapa $1 \triangleright$ Eje Atlántico

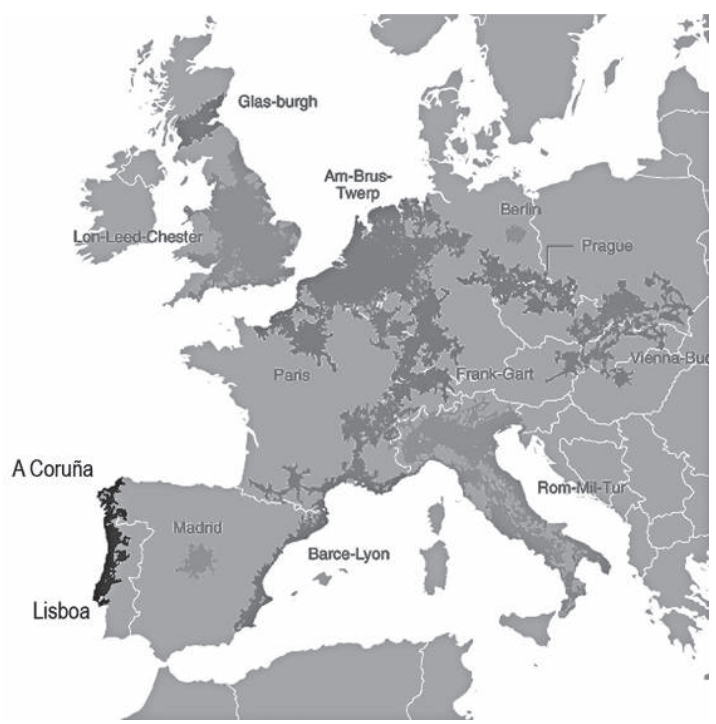

Fuente: Elaboración propia a partir del mapa de megarregiones europeas publicado por Richard Florida (Florida, 2009).

Imagen $2 \triangleright$ Figura en piedra de Santiago Matamoros coronando el frontón del Palacio de Rajoy en la ciudad de Santiago de Compostela

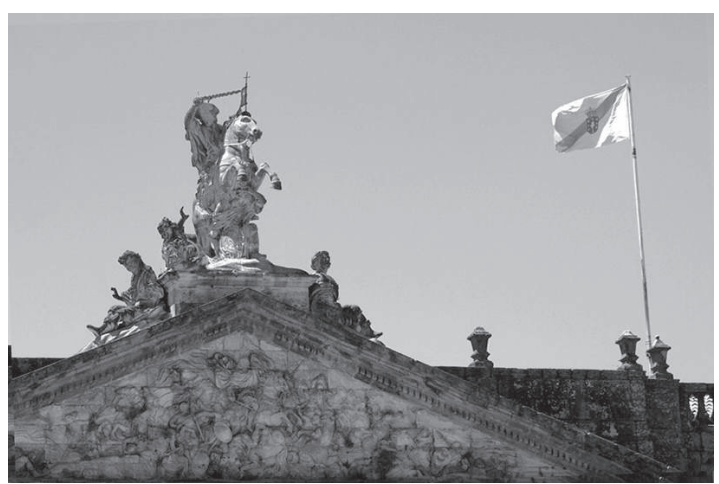

Fuente: Consultado en línea. Acceso en: <https://farm1.static.flickr. com/642/20622846734_336e624ed8_b.jpg>

El actual turismo religioso ha existido desde que existe el turismo, desde que esta actividad adquirió pleno desarrollo en los países del capitalismo avanzado. Pero evidentemente la modalidad del turismo religioso tiene unos orígenes premodernos, anteriores a la aparición de la ciudad capitalista. Aunque el salto temporal que se da entre Santiago y Fátima podría hacer difícil pensar en un análisis comparativo, trabajos como el de William A. Christian (Christian, 1978) podrían servir de ejemplo modélico en este sentido. La realización de largos viajes para visitar lugares sagrados, fue una práctica extendida por toda Europa desde la Edad Media. Estas migraciones rituales todavía vigentes suponen la continuación de una tradición ancestral al mismo tiempo que un lucrativo negocio que hoy se explota desde el marketing territorial. Llegados al punto actual, las historias particulares dejan de tener importancia a la hora de comparar las estrategias de promoción empleadas.

Con independencia de la fe que profesen los peregrinos, o de los motivos que convoquen a los turistas en estos espacios, alrededor de los grandes hitos religiosos se ha generado toda una serie de relaciones económicas con gran impacto en la transformación de las ciudades contemporáneas. Se podría argumentar que existen semejanzas entre el aura mística y sagrada que inspiran catedrales y museos. Es cierto que visitar una iglesia como turista y no como peregrino cambia por completo el sentido de nuestra acción. En cualquier caso, expondré que resulta razonable analizar coincidencias entre la experiencia de lo sagrado y la idea de trascendencia implícita en el viaje del turista. El efecto de descubrimiento y en ocasiones también el deseo de transformación interior asociado a esta actividad lúdica, hace de la elección de un lugar como destino turístico una acción que metafóricamente puede contemplarse como la búsqueda del propio destino. Tras pasar unos días en Lisboa, en el camino de vuelta hacia A Coruña decidí hacer un alto para visitar el Santuario de Fátima, allí terminé de recoger una serie de notas que finalmente dieron forma a este artículo.

En mi visita a Lisboa dediqué una buena parte de mi tiempo a deambular por la ciudad disfrutando del placer que proporciona perderse para ser sorprendido. Una de esas tardes sin rumbo, llegando a la freguesia ${ }^{2}$ de Alcántara (Mapa 2) me entero de la existencia de un nuevo espacio de ocio urbano: Lx Factory (Imágenes 3 y 4 ).

Sin saber nada sobre este lugar, me dirijo hacia allí. Es cierto que la percepción que uno tiene de un lugar depende de estados de ánimo, contexto de la situación por la que se accede a ese espacio y entre otras muchas cosas, de los referentes culturales que manejemos. Atendiendo a estos factores resultaría del todo improbable dar con dos percepciones iguales. También es cierto que en la medida en que un espacio ha sido diseñado, se ha tenido cuidado de simplificar y hacer más legible la descodificación de señales con la intención de facilitar una lectura "correcta". Con esto quiero recordar al lector que quienes promocionan un lugar para el consumo 
de ocio turístico se han preocupado previamente de diseñar el entorno y la disposición de todo el escenario con una clara intención comunicativa. Con el objetivo de conseguir conectar con el público visitante, habitualmente se recurre a imágenes arquetipo que constituyen referentes culturales globales compartidos por una inmensa mayoría de personas. Realizada esta puntualización, dedicaré los próximos párrafos a explicar por qué entendí que lo que se propone al visitante en Lx Factory es lo que muchos autores han calificado como espacio disneyficado (Bryman, 2004; Zukin, 1996). La hiperrealidad de "la estrategia de la ilusión" (Eco, 2012) ha producido en $L x$ Factory un no-lugar preñado de magia, un escenario ubicado fuera del tiempo histórico en el que se recrea una imagen idealizada del papel que la economía del talento ocupa en los escenarios urbanos posindustriales (Florida, 2009).

Mapa $2 \triangleright$ Flecha señalando la freguesia de Alcántara en el plano de Lisboa

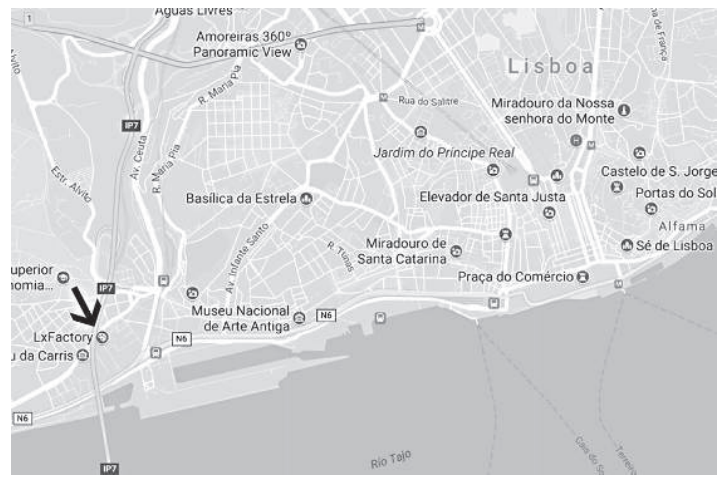

Fuente: Google Maps.

Imagen $3 \triangleright$ Letras sobre umbral de acceso, vistas desde dentro

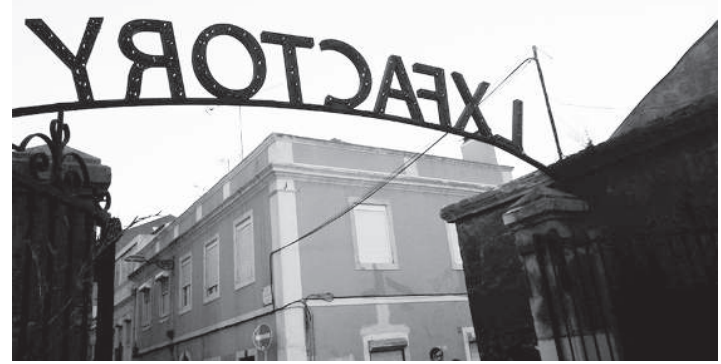

Fuente: Elaboración propia.

La impresión que este lugar plagado de graffiti (Imagen 5) proporciona al visitante, se aproxima a la idea globalmente difundida sobre Berlín a partir de mediados de la década de 1990. Desde esa fecha, las imágenes de antiguos espacios industriales ocupados ilegalmente por jóvenes de diferentes movimientos sociales, transmitieron todo un imaginario que representaba a Berlín como cuna de una realidad urbana radical y vanguardista. Una realidad local sometida a la regeneración forzosa provocada por la transformación del mapa geopolítico global tras la caída del famoso muro. En los últimos años, las estrategias de un urbanismo neoliberal que promueve el fenómeno de la gentrificación asociada al auge de las clases creativas (Florida, 2009), se han visto en Berlín claramente identificadas en el proceso de transformaciones que ha seguido el barrio de Kreuzberg (Sorando y Ardura, 2016, pp. 145-146).

Imagen $4 \triangleright$ Mapa de ubicación en la entrada. Detalle ampliado que muestra la vocación turística del espacio rehabilitado

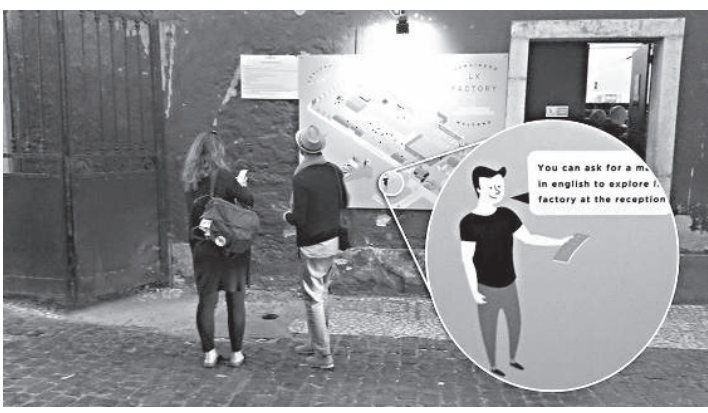

Fuente: Elaboración propia.

Imagen $5 \triangleright$ Tres de los muchos graffitis que se pueden ver en el interior del recinto

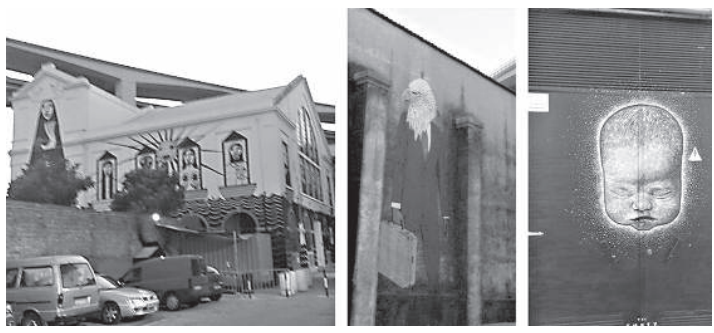

Fuente: Elaboración propia.

En Lisboa, la producción de Lx Factory como nuevo escenario urbano ha surgido de la regeneración de un antiguo conjunto fabril que, durante la segunda mitad del siglo XIX, motivó la aparición del primer barrio obrero. En el año 1846 la Compañía de Hilos y Tejidos de Lisboa iniciaba la actividad en este solar que a lo largo del siglo XX fue pasando por varios usos hasta que en 2008, en plena crisis económica, se transformó en "referencia mundial en rehabilitación de estructuras de fábricas". ${ }^{3}$ Mainside Investments ha sido la promotora privada encargada de insuflar nueva vida a esta área industrial 
degradada de $23.000 \mathrm{~m}^{2}$. Lx Factory se define en su página web de la siguiente manera:

Uma ilha criativa ocupada por empresas e profissionais da indústria também tem sido cenário de um diverso leque de acontecimentos nas áreas da moda, publicidade, comunicação, multimédia, arte, arquitectura, música, etc. gerando uma dinâmica que tem atraído inúmeros visitantes a redescobrir esta zona de Alcântara. Em LXF, a cada passo vive-se o ambiente industrial. Uma fábrica de experiências onde se torna possível intervir, pensar, produzir, apresentar ideias e produtos num lugar que é de todos, para todos. ${ }^{4}$

Este nuevo escenario se relaciona con un consumo alternativo ligado a tendencias globales que hacen de lo antiguo (vintage) un signo de distinción social ( $\mathrm{cool}$ ) dentro del hipsterismo, calificativo que recibe un amplio conjunto de prácticas estéticas que tienen sus orígenes en los estilos de vida de las grandes metrópolis de principios del siglo XXI (Lenore, 2014). En esta hipsterlandia que recrea el Berlín okupa de la década de 1990, la fantasía recubre los viejos muros con graffiti diseñados para dar a entender que son fruto de una fresca y espontánea expresión de repulsa de los ideales funcionalistas que han orientado el diseño de los centros comerciales convencionales. Al contrario que esos espacios concebidos como fábricas del consumo programado, $L x$ Factory representa una pequeña isla que resiste a los empujes de las corrientes mayoritarias (mainstream). La magia invocada en este paraíso posindustrial que concentra gran número de locales cuyo alquiler gestiona la promotora Mainside, necesitó del despliegue de todo un programa iconográfico acorde con el discurso corporativo que $L x$ Factory requería. Con tal fin se solicitó la intervención de la actividad de profesionales encargados del diseño de la identidad vinculada al lugar (Imagen 6$).^{5}$

Imagen $6 \triangleright$ Logotipo de LX Factory pintado en un depósito de agua

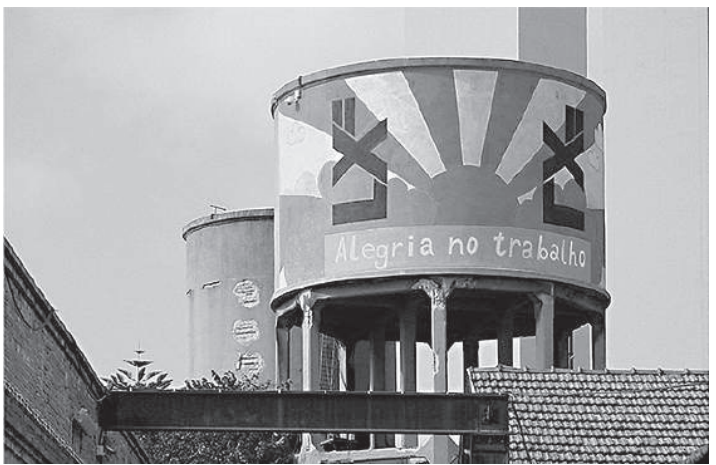

Fuente: Elaboración propia.
Como suele ser habitual en estos proyectos, uno de los primeros elementos de identidad que se modificaron fue la propia denominación. En este punto conviene aclarar que $L x$ es a Lisboa lo mismo que $B C N$ a Barcelona. El regenerado escenario presentado con una denominación que abandona la lengua portuguesa para hacer uso del vocablo inglés Factory, pretende de esta forma evocar su asociación con el famoso estudio de arte fundado por Andy Warhol. El hallazgo creativo de los encargados del trabajo de naming, metafóricamente condensa las claves del proceso de reconversión industrial que ha caracterizado a muchas de las economías urbanas de finales del siglo XX. El Arte y la Cultura son sistemáticamente invocados para que se produzca el milagro de la regeneración.

Hay un logro de la moderna antropología que no hemos de negar: el reconocimiento de que, magia y religión no son solamente doctrina o filosofía, ni cuerpo intelectual de opiniones, sino un modo especial de conducta, una actitud pragmática que han construido la razón, la voluntad y el sentimiento a la vez. De la misma suerte que es modo de acción, es sistema de credo y fenómeno sociológico además de experiencia personal. (Malinowsky, 1994, p. 5)

La actividad de la esfera económica por proveer de medios y recursos imprescindibles para satisfacer necesidades materiales de subsistencia, tradicionalmente se ha considerado la infraestructura que sustenta y sirve de base a toda organización social. El enfoque antropológico del materialismo cultural, entiende que la religión, el arte y otras producciones simbólicas integran aquello que se ha conceptualizado como la superestructura de las sociedades (Harris, 2014, p. 39). La distinción clásica entre infraestructura, estructura y superestructura resulta operativa en muchos aspectos porque permite aclarar la articulación de las conexiones que existen entre diferentes subsistemas culturales. Una cosmogonía que contemple a un dios del maíz difícilmente podría ser concebida en una comunidad en la que el cultivo de este cereal no fuese núcleo de la reproducción de su modo de vida. De esta manera, el modelo planteado por la teoría social marxista, se muestra útil para orientar el análisis cultural, otorgándole una coherencia holística que de otro modo no alcanzaría. Pero la radicalización de este planteamiento ha desembocado en ocasiones en la argumentación de que toda la producción en el nivel de la superestructura no representa más que el reflejo de lo que opera a nivel de la infraestructura. Al proceder según este razonamiento se obvia que el conjunto de ideas y creencias que constituyen lo económico debe considerarse también una producción 
tan simbólica como el conjunto de ideas y creencias que constituyen lo religioso.

Ninguna forma cultural puede ser leída a partir de un conjunto de 'fuerzas materiales' como si lo cultural fuese la variable dependiente de una ineludible lógica práctica. [...] no existe lógica material al margen del interés práctico, y el interés práctico de los hombres por la producción está constituido simbólicamente. (Sahlins, 1988, pp. 204-205)

En el primer libro de El Capital (escrito en 1867) se encuentra un epígrafe titulado "El fetichismo de la mercancía y su secreto" en donde Marx se detiene a ilustrar de qué manera las mercancías son algo más que objetos físicos (Marx, 2000, p. 101). En este pasaje se comprende que Marx en ningún momento desatendió el carácter simbólico que en el fondo subyace en toda la actividad productiva. La conversión de cualquier cosa en mercancía implica operaciones de la mente próximas a las que se dan en el ritual mágico. El valor de cambio no es más que metafísica: la transformación de la cosa en signo, la incardinación en lo material del elemento simbólico incorporado al objeto durante su producción (Godelier, 1990). Actualmente este carácter metafísico se manifiesta en el hecho de que gran parte de la comunicación que promociona las bondades de un producto, apela directa o indirectamente a una dimensión mágica. La publicidad se esfuerza por hacer de cualquier cosa un fetiche, un talismán que confiere al que lo posee alguna clase de poder. Cuando la publicidad promociona un espacio urbanizado resulta fácil comprobar cómo su discurso, antes que informar sobre la calidad de las infraestructuras, invocará el arquetipo del santuario o del paraíso. En este sentido, el espacio urbano representa el gran fetiche de la economía capitalista puesto que constituye el escenario en el que el resto de las mercancías se disponen para convocar a diferentes identidades sociales. La arquitectura urbana como contenedor de actividad social, es el medio a través del cual recibimos multitud de mensajes. La sobreexposición a este incesante torrente de estímulos, característico del estilo de vida urbano, (Simmel, 1986) provoca que apenas seamos conscientes de cómo el entorno determina nuestro comportamiento. Proxémica fue el nombre acuñado por Edward Hall para designar un conjunto de teorías que intentan dar cuenta de esta dimensión que permanece oculta (Hall, 1973). El efecto del medio en el que físicamente estamos envueltos es profundo y duradero. Los espacios a los que acceden los individuos constituyen una estructura base que sirve de soporte a piezas de comunicación cuyo mensaje tiene un efecto más incidental. Los espacios corporativos se diseñan para captar y dirigir la atención del público hacia elementos que sin proclamar nada explícitamente, consiguen evocar ideas y actitudes en consonancia con las actividades que allí se promueven. $L x$ Factory es un espacio regenerado según la lógica con la que opera el urbanismo corporativo especializado en la producción de barrios de marca. El branding entiende su labor como la correcta gestión de los intangibles que pueden ser activados por una corporación. Expertos y profesionales del mundo publicitario han expuesto cómo más de mil años antes de que se comenzase a hablar de branding, la Iglesia católica vendiendo pedazos de cielo, se convirtió en una de las primeras corporaciones multinacionales que se dedicó con éxito a la venta de intangibles (Toscani, 1996, pp. 131-145).

La diferencia que se establece entre un objeto cualquiera de nuestro entorno y un producto disponible en el mercado se encuentra en que este último únicamente puede existir por la mediación de un intercambio simbólico. La idea de que existe una producción cultural diferenciada de otra que no puede entrar dentro de esa categoría se basa en una distinción puramente ideológica. No es posible que exista una mercancía que no sea un producto cultural. La producción del espacio y su conversión en mercancía dentro de las sociedades capitalistas incluye siempre la explotación comercial de aspectos simbólicos intangibles. En la práctica resulta complejo asignar al simbolismo, incluso al religioso, una posición fija dentro de un sistema cultural. Sin abandonar la analogía arquitectónica, lo simbólico podría funcionar a modo de un ascensor conectando niveles infra y superestructurales. Los productos de la cultura material vendrían a ser botones del cuadro de mando de ese ascensor que moviliza y comunica la producción del significado.

El espacio urbano históricamente ha sido construcción material y, al mismo tiempo, producción simbólica de un intangible capaz de dotar de significado a la existencia. "El hecho de fundar una ciudad estaba en estrecha conexión con la constitución de una doctrina y por ello la ciudad era un símbolo de la misma" (Cirlot, 1992, p. 134). Para la mayor parte de los estudiosos de los fenómenos urbanos resulta incuestionable el vínculo que en su origen existió entre la ciudad y la religión. Recientemente las excavaciones de Göbekli Tepe en el sudeste de Turquía, han proporcionado evidencias arqueológicas que ponen en duda la existencia de una secuencia de fases que considera el sedentarismo y la aparición de las primeras ciudades, anterior al desarrollo de las instituciones religiosas. Al contrario de lo que se pensaba hasta hace unas décadas, Göbekli Tepe ha permitido constatar que la construcción de grandes templos se produjo mucho antes de que existiera algo parecido a una ciudad neolítica. "Lo que está claro es que nadie vivió en Göbekli Tepe" (Ellard, 2016, p. 8). La concepción arquitectónica de gran escala 
desconectada de la función residencial o productiva es probablemente algo tan antiguo como la propia existencia de grandes núcleos de población humana. Los sistemas de creencias religiosas sirvieron de fundamento a la construcción de espacios para el intercambio simbólico con entidades abstractas intangibles. Todos estos espacios de comunión colectiva fueron concebidos para la realización de unas prácticas rituales que nunca tuvieron relación directa con las necesidades derivadas de la reproducción social de los recursos y condiciones materiales que hacen posible la existencia. Pero esta característica no ha sido exclusiva de los lugares sagrados. Como ha señalado Johan Huizinga no resulta posible trazar líneas que establezcan divisiones netas entre las funciones consignadas a los espacios destinados al culto religioso y otro tipo de espacios de interacción social.

El sacramento y el misterio suponen un lugar consagrado. Por la forma, es lo mismo que este encercado se haga para un fin santo o por puro juego. La pista, el campo de tenis, el lugar marcado en el pavimento para el juego infantil de cielo e infierno, y el tablero de ajedrez no se diferencian, formalmente, del templo ni del círculo mágico. [...] Si resulta que la acción sacra apenas se puede diferenciar formalmente del juego, se plantea entonces la cuestión de si esta coincidencia entre el culto y el juego no se extenderá más allá del aspecto puramente formal. (Huizinga, 2007, p. 36)

En los últimos años, sociólogos centrados en el estudio de los fenómenos urbanos contemporáneos han comenzado a hablar de un creciente proceso de ludificación (Baptista, 2005). La tendencia asociada a este proceso conlleva la producción urbanística de todo el espacio como territorio destinado a la actividad lúdica. Al abordar las transformaciones urbanas que se dan en espacios regenerados al estilo de $L x$ Factory, conceptos como ludificación y disneyficación permiten explicar parte de las dinámicas por las que se han integrado variantes del pensamiento mágico y religioso en la producción de un mercado inmobiliario que explota el pasado histórico a partir del consumo de fragmentos de su ruina. De hecho para la ciudad de Lisboa existen análisis que desde los enfoques de la geografía urbana han destacado cómo el deterioro y el abandono de ciertos espacios de la vieja ciudad industrial ha posibilitado la aparición de una oferta de ocio que hunde sus raíces en la estetización de lo sórdido y lo marginal (Nofre, 2013). El antropólogo catalán Manuel Delgado a menudo ha empleado el término "exorcismo" para referirse al modo en que las políticas urbanas neoliberales construyen su representación del supuesto milagro que tiene lugar durante el proceso de gentrificación que transforma un barrio degradado (Delgado, 2008). Se trata del misticismo retórico de un urbanismo de marca que hace uso de estrategias de higienismo social para la expulsión de un "maligno" que no es otro más que aquel vecino cuya presencia supone un obstáculo a la hora de conseguir que el barrio sea incluido en circuitos turísticos. Existen conexiones evidentes entre gentrificación, ludificación y ciertos procesos de sacralización que las políticas culturales activan por la vía de la intervención artística del espacio. Esta conexión resulta obvia hasta el punto de que Condé Nast Traveller, una revista turística destinada al gran público, ha difundido información sobre lugares como $L x$ Factory recurriendo a titulares como: "Menos humos y más cultura: el atlas mundial de las fábricas resucitadas". ${ }^{6}$

Como comentaba al principio de este artículo, mi experiencia como turista en la ciudad de Lisboa estuvo marcada por el hallazgo casual que me proporcionó un mapa guía de la ciudad en el que FreePort (centro de shopping) y el Santuario de Fátima aparecían equiparados como espacios idóneos para el consumo de ocio turístico. La reflexión sobre esta convergencia entre urbanismo, religión y turismo me acompañó a lo largo de mis recorridos por la ciudad y desencadenó que en mi viaje de regreso decidiese visitar Fátima. Desconocedor de la historia del lugar, tras aparcar el coche en un área habilitada para tal fin en las inmediaciones del Santuario, fui sorprendido en primer lugar por unas banderolas que celebraban los 100 años de la aparición de la Virgen en ese lugar (Imagen 7).

La antigua parroquia rural que era Fátima en 1917 hoy se ha desarrollado hasta el punto de que esta localidad ha sido estudiada como núcleo turístico con unas bases de organización territorial y funcional que "no diferían en exceso de aquellas otras que se definen para destinos clásicos de sol y playa" (Santos Solla, 2015). Al margen de la concepción de todo el complejo como escenario para el espectáculo de masas, a través de un diseño espacial que se aproxima a la tipología morfológica del estadio deportivo (Imagen 8), y dejando a un lado el hecho de que los puestos de venta de suvenires y artículos religiosos hayan crecido hasta convertirse en un auténtico centro comercial (Imagen 9), todas las coincidencias que se puedan establecer entre el Santuario y un parque temático se quedan cortas ante el hecho de que allí se encuentre una singular e insólita reliquia (Imagen 10). Forzosamente el visitante tiene que admirarse ante la contemplación de un módulo de hormigón del muro de Berlín que se muestra encapsulado dentro de una colosal vitrina de cristal. La búsqueda de información que a posteriori realizo para conocer los pormenores de esta historia me hace saber que: 
Imagen $7 \triangleright$ Banderola del centenario

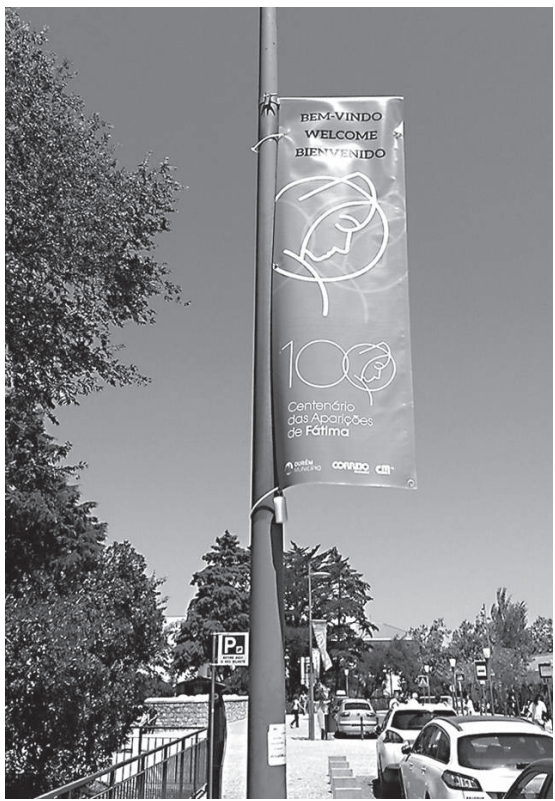

Fuente: Elaboración propia.

En marzo de 1991, cruzaba la aduana portuguesa un enorme bloque del Muro que hoy se expone junto a una entrada de la explanada del santuario portugués. Lo habían costeado portugueses dirigidos por Virgilio Ferreira. Pesaba 2.600 libras, tiene 3,6 m de alto y 1,2 de ancho. El consulado portugués en Frankfurt y el centro de turismo portugués de esa ciudad ayudaron en la operación. El muro había durado 28 años... y ese fragmento se exponía, como un despojo, un símbolo de la fragilidad de los imperios humanos, en la casa de la Virgen. ${ }^{7}$

Imagen $8 \triangleright$ Muchedumbre congregada en el recinto de oración y detalle del plano que se facilita a los visitantes

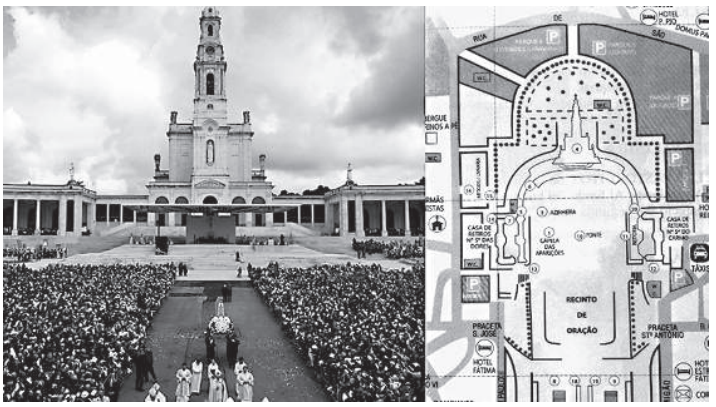

Fuente: Fotografía consultada en línea. Acceso en: http://www. noticiasrcn.com/sites/default/files/styles/juicebox_medium/ public/galeria_imagenes/6 385.jpg?itok=9W2MqOBB
Imagen $9 \triangleright$ Centro comercial de artículos religiosos en Fátima

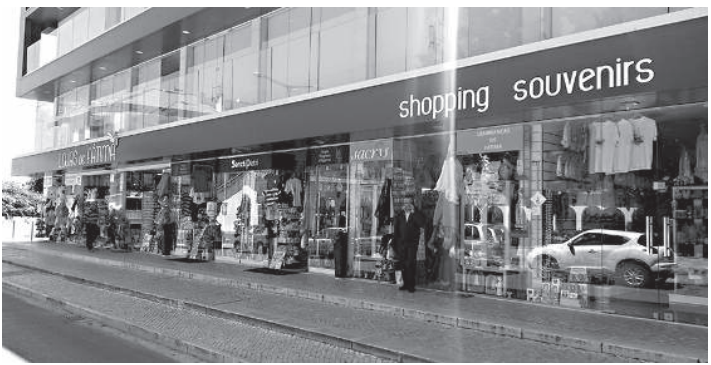

Fuente: Elaboración propia.

Imagen $10 \triangleright$ Fragmento del muro de Berlín expuesto como reliquia

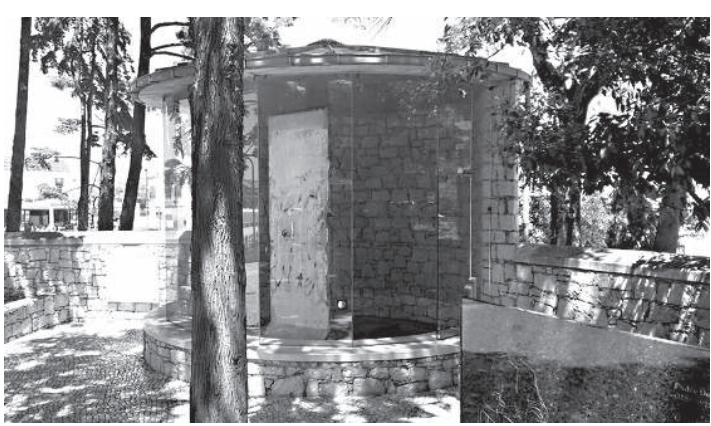

Fuente: Elaboración propia.

Este episodio que visto aisladamente puede aparentar un esperpento, alcanza un significado más cabal cuando es contemplado dentro de un marco temporal más amplio, como parte de un proceso de instrumentalización política que se ha desarrollado a largo plazo. Si ya entre las primeras advertencias de la Virgen aparecida en 1917, supuestamente se hacía mención al final que tendría la revolución bolchevique, desde finales de la década de 1950 el camino seguido por los pastorcillos fue habilitado (urbanizado) como Via Crucis gracias a la financiación de los católicos húngaros que de este modo expresaron su rechazo a la represión soviética en Budapest de $1956 .^{8}$

\section{Reflexión final a modo de conclusión}

A principios de la década de 1990 la crítica del ecologismo radical buscó en cierto reencantamiento del mundo una salida a los problemas éticos derivados de la mercantilización de toda la vida natural y social. Las propias religiones en el mercado capitalista eran vistas como opciones de consumo vinculadas a una serie de productos y servicios cuya demanda fluctuaba según oferta y demanda. Libros como "En ausencia de lo sagrado" (Mander, 1996) proponían que la crisis ecológica planetaria en la que estamos 
inmersos era una consecuencia directa del triunfo de la racionalidad del hombre blanco que intentaba forzar al resto de pueblos del planeta a cortar lazos con la esfera de lo sagrado. Se hacía referencia a la pérdida de cierta religiosidad que todavía podía ser rescatada si retomando la sabiduría de los pueblos indígenas, volvemos a comulgar con la Naturaleza. En gran parte de los movimientos altermundistas, se cultivó algún tipo de conciencia moral plagada de buenas dosis de misticismo. Actualmente parece algo muy evidente el hecho de que la lógica cultural de las principales economías urbanas globalizadas, ha conseguido regenerarse precisamente gracias a que la producción creativa de nuevas dinámicas identitarias ha asimilado con éxito viejas fórmulas del pensamiento mágico y religioso.

Al mismo tiempo, la oferta de artefactos simbólicos producidos para el mercado religioso ha evolucionado desde antiguas reliquias medievales que habitualmente consistieron en fragmentos de huesos u otras partes incorruptibles de la anatomía de santos y vírgenes, hasta incluir hoy día los restos fragmentados de una moderna ruina industrial. Que esto se haya producido dentro de la propia Iglesia Católica y contando con el respaldo del Papado, constituye un elocuente argumento que permite dilucidar algo sobre los mecanismos que ha activado el branding a la hora de revalorizar escenarios urbanos posindustriales apelando a un componente mágico religioso. Desde que el enfoque del marketing territorial comenzó a orientar la gestión de los espacios urbanos, el trabajo de las industrias creativas ha consistido en buena medida en volver a introducir lo sagrado en el corazón del mercado inmobiliario. A partir de esta reflexión es posible concluir que convendría repensar las conexiones que en las sociedades capitalistas contemporáneas la religión ha establecido con el mercado inmobiliario y viceversa. Lx Factory localiza en Lisboa estrategias de place branding adaptadas a las lógicas de un urbanismo global que está operando en todas las ciudades a partir de activar las mismas dinámicas de reconversión de identidades. La realidad observada en este caso concreto nos permite confirmar la necesidad de incorporar el estudio de aspectos mágicos o religiosos en los análisis culturales que intentan dar cuenta de estas dinámicas de regeneración urbana. Lx Factory y similares lugares disneyficados solo pueden ser plenamente comprendidos a partir de análisis económicos de la evolución de los mercados que más allá de aceptar la magia como metáfora creativa, empiecen a profundizar en la comprensión de los mecanismos por los cuales se activa la fe en creencias religiosas.

\section{Notas}

1 Varias personas colaboraron de diferentes formas en la redacción de este texto. Quiero expresar mi agradecimiento a Luís Vicente Baptista por la amabilidad con la que me recibió en la Universidade Nova de Lisboa, a Jordi Nofre quiero agradecer la visita guíada y la reflexión compartida sobre la geografía nocturna del Bairro Alto, y especialmente agradezco a José María Cardesín, profesor catedrático de historia de los movimientos sociales en A Coruña, los apuntes y comentarios que ayudaron a clarificar muchas de las ideas contenidas en este artículo.

2 En Portugal las freguesias, en ocasiones traducidas al español con el término feligresía o parroquia, son las unidades territoriales administrativas en las que oficialmente se puede subdividir un municipio.

3 EFE (02/06/2015). Consultado en línea el 28/09/2017. Acceso en: https://www.efe.com/efe/america/cultura/ Ix-factory-la-fabrica-de-ideas-y-experiencias-artisticas-lisboa/20000009-2628686.

4 LX FACTORY, página web. Consultado en línea el 28/09/2017. Acceso en: http://www.Ixfactory.com/PT/ |xfactory/.

5 En concreto, el estudio de diseño y comunicación gráfica Cunha Leão fue el encargado de desarrollar en gran medida la identidad visual de este espacio multifuncional. Página web consultada el 28/09/2017. Acceso en:http:// www.cunhaleao.com/PT/cunha-leao/.

6 CONDE NAST TRAVELER. Consultado en línea el 28/09/2017. Acceso en: <http://www.traveler.es/viajes/ rankings/galerias/fabricas-resucitadas-el-atlas-mundial-de-una-generacion/855/mosaico/1> [La cursiva es nuestra].

7 RELIGIÓN EN LIBERTAD. Página web consultada el 28/09/2017. Acceso en: http://www.religionenlibertad.com/la-virgen-de-fatima-fue-al-muro-de-berlin-en-1978-38699.htm.

8 SANTUARIO DE FÁTIMA. Página web oficial consultada el 09/07/2018. Acceso en: < https://www.fatima.pt/es/ pages/lugares-de-culto-y-oracion.

\section{Referencias bibliográficas}

Baptista, L. V. (2005). Territórios lúdicos (e o que torna lúdico um território): Ensaiando um ponto de partida. Forum Sociológico, (13-14), 47-58.

Bryman, A. (2004). The disneyization of society. Editorial Sage.

Christian, W. A. (1978). Religiosidad popular. Estudio antropológico en un valle español. Madrid: Tecnos.

Cirlot, J. E. (1992). Diccionario de símbolos. Barcelona: Editorial Labor.

Delgado, M. (2003). Naturalismo y realismo en etnografía urbana. Cuestiones metodológicas para una antropología de las calles. Revista Colombiana de Antropología, (39), 7-39.

Delgado, M. (2008). La artistización de las políticas urbanas. El lugar de la cultura en las dinámicas de reapropiación capitalista de la ciudad. Scripta Nova. Revista Electrónica de Geografía y Ciencias Sociales, XII(270). 
Eco, U. (Ed.) (2012). Viaje a la hiperrealidad. In La estrategia de la ilusión (pp. 15-82). Barcelona: Debolsillo.

Ellard, C. (2016). Psicogeografía: La influencia de los lugares en la mente y el corazón. Barcelona: Grupo Planeta.

Florida, R. (2009). Las ciudades creativas: Por qué donde vives puede ser la decisión más importante de tu vida. Barcelona: Paidós.

Godelier, M. (1990). Lo ideal y lo material. Madrid: Taurus.

Hall, E. T. (1973). La dimensión oculta. México: Siglo XXI.

Harris, M. (2014). Antropología cultural. Madrid: Alianza.

Harvey, D. (Ed.) (2007). De la gestión al empresarialismo: La transformación de la gobernanza urbana en el capitalismo tardío. In Espacios del capital: Hacia una geografía crítica. Madrid: Akal.

Huizinga, J. (2007 [1945]). Homo ludens. Madrid: Alianza Editorial.

Lenore, V. (2014). Indies, hipsters y gafapastas: Crónica de una dominación cultural. Madrid: Capitán Swing.

Malinowsky, B. (1994). Magia, ciencia, religión. Barcelona: Ariel.

Mander, J. (1996). En ausencia de lo sagrado: El fracaso de la tecnología y la supervivencia de las naciones indias. In J. J. de Olañeta (Ed.). España: Palma de Mallorca.

Marx, K. (2000 [1867]). El capital: Crítica de la economía política (Vol. 1). Madrid: Akal.

Nofre, J. (2013). De lo sórdido a lo vintage, de la marginalización a la distinción. Gentrificación y ocio nocturno en Cais do Sodré, Lisboa. Forum Sociológico, (23), 59-67.

Sahlins, M. (1988 [1976]). Cultura y razón práctica. Barcelona: Gedisa.

Santos Solla, X. M. (2015). Reflejos territoriales en destinos religiosos y de sol y playa. De Fátima a Benidorm. Investigaciones Turísticas, 9, 184-203.

Simmel, G. (1986 [1903]). Las grandes ciudades y la vida del espíritu. Revista Cuadernos Políticos, (45), 5-10.

Sorando, D., y Ardura, Á. (2016). First we take Manhattan: Se vende ciudad. La destrucción creativa de las ciudades. Madrid: Catarata.

Tetlow, J., Okland, R., y Myers, B. (2011 [2007]). Queen of all - Reina de todos. Ontario: Chick Publications.

Toscani, O. (Ed.) (1996). Cruz, esvástica, coca-cola. In Adiós a la publicidad (pp. 131-145). Barcelona: Ediciones Omega.

Zukin, S. (1996). The cultures of cities. Editorial Blackwell.

Recebido a 29/09/2017. Aceite para publicação a 15/06/2018.

Samuel Fernández Ignacio (samuel.fernandez.ignacio@edu.xunta.es). Doctor en Sociología por la Universidad de A Coruña. Actualmente reside en A Coruña y trabaja en la misma ciudad como profesor interino de la especialidad de diseño gráfico en la Escuela de Arte y Superior de Diseño Pablo Picasso. C/ de la merced, n 1, $9^{\circ}$ B. A Coruña, 15009 España. 